IP Periodica Polytechnica

Social and Management

Sciences

26(1), pp. 79-86, 2018

https://doi.org/10.3311/PPso.10706

Creative Commons Attribution (i)

RESEARCH ARTICLE

\section{Needed but Rejected: How to Implement the Financial Stability Objective into Monetary Policy?}

\author{
Tamás Pál ${ }^{1}$, Gabriella Lamanda ${ }^{1 *}$
}

Received 06 March 2017; accepted after revision 27 March 2017

\begin{abstract}
The 2008 crisis forced central bankers and the representatives of academic literature to reassess the prevailing consensus on practice of monetary policy. Among other topics, the spotlight also fell on the question that how financial stability must be treated. Debate renewed on whether the central bank must play an active role in preventing and managing market turmoil, which consists of leaning against the wind of markets. This paper summarises opinions on this issue and offers our own conclusions. We found that currently neither the theoretical background nor empirical experience provide compelling evidence or a reference for central bankers to move away from their existing monetary policy framework and adopt a leaning against the wind policy. We conclude that the direct integration of financial stability considerations into monetary policy decision-making - i.e. as a form of rules - is not expected in the near future. However, we think that the debate remains open for two reasons: firstly, there is some uncertainty regarding the success of macroprudential regulation and its proper cooperation with monetary policy and secondly, the theoretical development of the implementation of financial cycles into monetary decision-making may also yield results.
\end{abstract}

\section{Keywords}

monetary policy, financial stability, macroprudential policy

\section{Introduction}

Prior to the crisis, monetary policy in the developed world was simple in the sense that its role, basic objective and toolset were based on broad consensus spanning academia, markets and economic policymakers. The macroeconomic results justified all of the above: price stability and more stable business cycles confirmed the adequacy of monetary policy thinking. However, the crisis created such challenges for monetary policy that theoretical researchers, central bankers and economic policymakers were forced to revise the earlier comfortable consensus. Debate re-emerged between the proponents of leaning against the wind and of clean-up strategies too.

The aim of this article is to summarise the questions on how financial stability must be treated that may be decisive in terms of the future of monetary policy. We present the often conflicting views and opinions on the main issues along this topic.

There is consensus that financial stability must be treated as a priority; but there remains disagreement as to the form in which this should be achieved: integrated directly into or separately from the monetary policy decision-making. In the latter case monetary policy only makes ex-post interventions when needed, in keeping with earlier practice. The essence of the leaning against the wind (LATW) policy is that the central bank plays an active role in preventing and managing market turmoil with taking into account the financial cycles in decision-making, which often consists of leaning against the wind of markets (Woodford, 2012). ${ }^{1}$ The other approach makes a clear distinction between the conventional (price stability) objective and the objective of financial stability. Within this framework, the price stability objective is the mandate of monetary policy while financial stability is the mandate of macroprudential policy. Stark (2010) emphasises that the sector-specific applicability of the macroprudential policy toolset is one of its greatest advantages. These tools include rules that shape the lending capacity and liquidity position of financial intermediaries - mainly

1 For instance, in the event of a significant credit outflow and asset price increases, the central bank maintains a higher interest rate than warranted by the purely conventional objective. 
banks - and the requirements designed to control household indebtedness. Supporters of the LATW policy consider macroprudential tools necessary and important, but they reject their exclusive use for managing financial stability risks. Based on our knowledge so far, or perhaps precisely in the absence of elaborated theoretical basement and relevant experience, the latter approach, i.e. managing the two objectives separately, seems to be gaining more ground. Furthermore, there are no clear answers to numerous questions, such as how LATW policy can be implemented in practice, what changes would it generate in central bank operation and what would be the real economic impact of an interest rate level that is higher than the one needed to achieve the inflation target. Meanwhile, questions also abound regarding the use of macroprudential tools. As they are largely new tools, their correct calibration is also uncertain and consequently, their impact on financial markets and the real economy is unknown. In other words, we think that choosing between the two ways of securing financial stability has been not finalised yet, even if the current practice and institutional reform have clearly resulted in the distinction between the two objectives.

\section{Financial stability}

The spotlight fell on financial stability as a monetary policy objective both for central bankers and academia in relation to the 2007-2008 crisis. Previously, it was widely accepted that a monetary regime aiming for price stability would also foster financial stability. In practice, this meant that the financial stability objective only existed implicitly within central bank thinking, while the objective of price stability was the priority. In addition, it was consensually linked in a narrower sense to the lender of last resort (LoLR) as a role of the central bank, associated with the freezing up of interbank markets (Blot et al., 2015). This is known as the clean-up strategy. Under financial stress, central banks mop up turmoil in the role of LoLR by extending conventional tools; in other words, by providing abundant liquidity and maintaining accommodative conditions.

Toniolo and White (2015) provide an overview of the development of the mandate of financial stability. The role of central banks as lenders of last resort emerged as early as the second half of the 19th century as liquidity crisis triggered by individual bank failures represented a financial stability risk. This required intervention from central banks in order to protect the system of financial intermediation and led to the emergence of the central bank role of lender of last resort. After World War II, direct bank regulation was given a central role in ensuring financial stability, in the form of administrative control and restrictions on lending, on interest rates and on international capital flows. After the disintegration of the Bretton-Woods system, the creation of the Basel Committee on Banking Supervision marked a new direction for regulation. The period leading up to the recent crisis was characterised by the focus of the authorities on individual institutions mainly, while the stability of the overall financial system was not given enough attention. ${ }^{2}$

Before the crisis, central banks' views on asset price bubbles as a cause of financial instability were based on the JacksonHole consensus reflecting the American approach that emerged during the Greenspan era. According to this approach, while asset price developments serve as an important indicator for monetary policy, central banks only intervene in market processes if these affect the inflation target. Accordingly, the main task of central banks was limited to restoring order after asset price bubbles burst, in the course of which they provided the liquidity necessary for market clean-up (referred to as the clean-up strategy).

In addition, prior to the global financial crisis, experience seemed to confirm the correctness of the principle (for example the restoration of market liquidity following the collapse of LTCM or the dot.com bubble). This consensus endured because monetary policy was successful in terms of its fundamental objective. However, the experience of the crisis shed light on the shortcomings of this approach. Prior to the recent crisis, financial instability emerged despite the attainment of monetary policy objectives during a period of price stability and was accompanied by consequences of unexpected magnitude. After the crisis, heated debate emerged on what made central banks wrong that played a role in emerging financial instability and what could have they done to prevent it. Amongst others, Woodford (2012) and Yellen (2014) both emphasise that monetary authorities failed to recognise the financial imbalances that preceded the crisis and how severe macroeconomic consequences they could lead to. It therefore became clear that ensuring price stability was not sufficient in itself to prevent the formation of financial instability, and the ex-post clean-up strategy aimed at dealing with this instability was insufficient for handling the issue. Monetary policy should alter its orientation in a way that also factors in the criterion of financial stability. However, there is no consensus as to the form and degree of this reorientation.

Initial critics to the effect that inflation targeting was a flawed monetary regime ceased relatively quickly. There seems to be broad consensus in that flexible inflation targeting is not only the way forward, but also plays a key role in offsetting the risks of the unconventional tools applied after the crisis (CEPR, 2013).

Accordingly, the debate was focused on pre-emptive action against financial instability and potential paths to avoid the emergence of asset price bubbles. Opinions that the central bank must play an active role in preventing and managing market turmoil, which consists of leaning against the wind of

2 It should be noted that what is referred to as microprudential regulation and supervision had its own shortfalls, as highlighted amongst others by the de Larosière report (http://ec.europa.eu/internal_market/finances/docs/ de_larosiere_report_en.pdf). 
markets, gained traction. Whether ensuring financial stability should be added to the central bank's competence list was at the centre of both academic debate and among practitioners. Meanwhile, the macroprudential line of defence for financial stability was created. (IMF, 2015.)

Two main approaches can be summarised based on the papers $^{3}$ - Smets (2014) and IMF (2015) — of the debates of recent years:

- Implementing LATW in monetary decision-making: It entails the adoption of guaranteeing financial stability as an additional monetary policy objective supplementing the objective of price stability. If financial cycles are factored in, when the central bank perceives a significant outflow of credit and asset price increases, it will temporarily maintain a higher interest rate than required by the purely conventional objective. This assumes that financial stability can be affected through interest rates. ${ }^{4}$ Proponents of this approach do not reject the use of the macroprudential toolset but consider it insufficient to handle market turmoil in and of itself. However, incorporating financial instability directly into decision support models is essential for conducting active central bank policy regarding the LATW.

- The modified Jackson Hole consensus: In essence, it consists of handling price and financial stability objectives separately from each other, the former constituting the mandate of monetary policy and the latter constituting the mandate of macroprudential policy. Macroprudential policy is a regulatory and supervisory framework that is aimed at addressing systemic financial risks ${ }^{5}$ and minimising the resulting losses. Its toolset comprises mainly capital and liquidity rules pertaining to the financial sector that can be used to take pre-emptive, preventive targeted action against the emergence of financial instability. Advocates of this view believe that macroprudential policy is capable of meaningfully and effectively shaping lending cycles and risk-taking, while monetary policy lacks the suitable tools. This also means that the monetary policy framework remains largely unchanged in terms of the clearly distinguishable set of objectives and toolsets of the two areas.

3 These papers summarise and review the researches made in this field.

4 For example: through its impact on leveraging and risk-taking and on the rise in market prices.

5 Systemic financial risk mainly refers to flaws within the financial system that carry the risk of an unexpected event, potentially one affecting an individual institution (such as bankruptcy), that triggers a crisis in a significant part of the financial sector, affecting its proper functioning to an extent that severely impacts the real economy.

\section{Leaning against the wind}

It must be clarified in advance that supporters of the LATW policy do not reject the need to use macroprudential tools (even outside central bank competence); on the contrary, they consider their joint application necessary to supplement the LATW policy. In Sweden and Norway, the two countries mentioned later in this paper as practical examples, numerous macroprudential policy tools were introduced also beyond the central bank's mandate ${ }^{6}$; in other words LATW is not the sole means for handling stability risks. Woodford states (referencing (Woodford (2012)) that macroprudential tools simultaneously improve financial stability and support the central bank in achieving its price stability objective. This does not mean however, that financial stability risks can be ignored in monetary policy decision-making. The main reason is that monetary policy has a significant impact on these risks through changes in the interest rate. In addition, the crisis clearly revealed the shortcomings of financial regulation and supervision beyond the absence of macroprudential regulation, including, among other things, the deficiencies of the comprehensive, uniform supervisory methodology, international coordination and regulation lagging behind financial innovation. According to a third argument, the absence of experience and knowledge about macroprudential tools is reason enough for the monetary authority to assume an active role in guaranteeing financial stability. (Olsen, 2015.)

Papers emphasising the significance of monetary policy actions offsetting asset price increases seek the way to incorporate financial stability objectives into conventional stability objectives (stability of the real economy) without fundamentally changing the current regime (Woodford (2012). The success of this multiple mandate relies on two key conditions. For one, financial variables must be incorporated into monetary policy decision-making. Secondly, assigning a financial stability mandate to the monetary authority must by definition be accompanied by an expansion of the time horizon of monetary policy (from the conventional 2-3 year horizon). (Woodford, 2012.)

A common trait of the efforts to incorporate financial stability into macroeconomic models and respectively into monetary policy objective and reaction function is that they attempt to supplement existing conventional frameworks with a variable or multiple variables sensitive to changes in financial stability risks.

6 Amongst other things, the introduction of the Basel III framework is underway, while in Norway are laws in place that define the maximum LTV ratio applicable to household loans. During the introduction of Basel III Sweden has established the Financial Stability Council with the representing members of the financial supervisory authority, the central bank and the state debt management agency, which continuously monitors financial stability risks and issues proposals for addressing imbalances. 
Woodford (2012) does not consider it necessary for the central bank to monitor market price developments or to estimate the divergence of asset prices from their fundamental value. In his simplified model, optimal monetary policy is demonstrated based on the relationship between three variables. Besides inflation and the output gap, the third variable to be introduced quantifies the expected losses stemming from growing leverage in the event of a financial crisis. ${ }^{7}$ Other authors also use variables expressing leverage. In their paper, Borio et al. (2016) conclude based on US data for the period of 1985-2015 that a LATW policy would have resulted in a higher growth path less prone to fluctuations, and in a less aggressive financial cycle. At the same time, they warned of the need for systematic policy that takes action consistently - not only when financial imbalances become apparent - and takes into account the entire financial cycle when conducting monetary policy. In their paper, Gelain et al. (2015) demonstrate that the proper choice of variables describing financial instability may be pivotal in terms of the outcome, a fact that must be taken into consideration. ${ }^{8}$

While the referenced studies attempt to justify the LATW policy, the practical implementation of their findings are still a long way off, even according to the authors. The IMF (2015) paper summarises the research conducted up to that point and comes to a similar conclusion, emphasising that models capturing financial market instability and its management within monetary policy are not only overly simplified and require significant improvement, but the estimated benefit of pursuing an LATW policy is small according to the majority of available models. Unless a severe crisis occurs, the policy's macroeconomic costs arising from the higher interest rates exceed the benefits derived from the decreasing frequency of crises. ${ }^{9}$ Nonetheless, Svensson (2016) warns that LATW does not unequivocally decrease the frequency of crises. In theory, higher interest rates curb real debt growth rate and thus financial stability risks; in other words, the probability of crises; however, several factors may dampen this expected impact. ${ }^{10}$

7 This is expressed by marginal crisis risk; for the construction of the model, see: Woodford (2012).

8 Based on their DSGE model, the authors investigated the impact of monetary policy decisions and measures aimed at the smoothing out of lending cycles. They conclude that if the central banks' key policy rate hikes are based on a high or growing loan-to-GDP ratio and real debt, it may exert a destabilising effect. They also found that if monetary policy aims to stabilise the volume of debt, the stock of new loans or the rate of credit growth are the most effective indicators for supporting decisions, and ultimately for fulfilling the mandate of financial stability.

9 However, the IMF (2015) study also suggests that the severity of financial crises may also decrease, alongside their frequency, which may warrant further research.

10 The author argues that first, if we accept the long-term neutrality of monetary policy, it means that we also accept that the key policy rate is unable to change the growth rate of real debt in the long run. Moreover, several papers cited by the author come to the conclusion that higher interest rates often
Overall, the cost-benefit analysis concludes that the macroeconomic costs of a central bank policy that aims to decrease the risk of financial instability using the traditional tool of the interest rate far exceed the expected outcomes of managing financial stability risks.

It should also be mentioned that an LATW policy may also have a negative impact on central bank credibility, which may result in inflation expectations coming loose from their anchor. According to the IMF (2015), the threat resides in the fact that financial stability is difficult to forecast and it is not fully built upon precisely defined variables, which impairs transparency and renders communication difficult. Svensson (2016) emphasises two cases when LATW may be undermined: for one the possibility of triggering deflation due to the pre-emptive action made by the central bank in order to ensure financial stability; second loss on central bank reputation if a financial crisis emerges despite the effort of the central bank. However, positive impact of LATW on credibility also can be used as an argument against these elements. According to Issing (2009), the clean-up strategy generates moral hazard: the role of lender of last resort spurs risk-taking in the markets and the abundant liquidity created to back a bailout to avoid macroeconomic losses creates a hotbed for repeated market instability. LATW is expected to reduce the frequency and degree of the need for such bailouts, so the moral hazard can be mitigated which, in turn, reinforces central bank credibility.

An additional challenge is that when conducting an LATW policy, the substantial impact on financial stability of numerous financial institutions outside the central bank's monetary system must also be factored in. In other words, assigning the mandate of financial stability to the central bank also requires an extension of central bank competence beyond the banks. This is a particularly central question in a capital market oriented economy. As the crisis has shown, capital market players play a pivotal role in destabilisation. As a result of this numerous unconventional tools were targeted specifically at these segments. The economists of the Bank of England (Nelson et al., 2015) warn that firstly, an LATW policy is limited in terms of the degree to which it is able to influence the growth of the balance sheets of financial intermediaries - it is capable to affect primarily the banks -, and secondly, it may bolster the growth of the shadow banking system through its negative impact on the traditional banking system (such as higher funding costs).

Central bank practice applied following the financial crisis also provided valuable experience. After the crisis, the practice of the Swedish and the Norwegian central bank was to factor

increase rather than decrease the proportion of real debt relative to GDP. It is true that a higher key policy rate may in fact reduce nominal outstanding loans and inflation, the latter even to a greater degree and at a faster rate, which may result in an unchanged real debt or even an increase in it. Thirdly, it cannot be ignored that credit growth is influenced by other factors besides interest rates too. 
in financial stability criteria along those of LATW in their decision-making. From 2010 onwards, the focus shifted in both countries to preventing excessive household indebtedness, as the primary indicator of financial risks. However, setting the key policy rate above what was required to meet the inflation target did not yield the desired results, and it was not therefore maintainable in the long run. First, it led to negative macroeconomic consequences. In Sweden's case, inflation fell significantly below the target value, while the unemployment rate was above target. In Norway, a significant decline in oil prices brought inflation temporarily below target, exerting significant pressure on the central bank. Meanwhile, the fact that interest rates higher than those in many other countries resulted in the appreciation of the domestic currency through more intensive capital inflows and that also created a challenge. In addition, no meaningful improvement was achieved compared to earlier trends in financial stability. The rise in household indebtedness could not be curbed and housing prices were continuously on the rise in both countries (Svensson, 2014 and Olsen, 2015). ${ }^{11}$ In other words, for the time being, Sweden and Norway practice has so far failed to justify this policy.

\section{The modified Jackson Hole consensus}

Supporters of the modified Jackson Hole consensus believe that price stability and financial stability objectives must be handled separately both institutionally (the latter should be independent from other central bank roles, entrusted to a separate body) and in terms of the applied tools. Price stability should be the mandate of the monetary authority, while financial stability should fall in the competence of the macroprudential authority. Macroprudential policy is therefore an independent regulatory and supervisory framework that is aimed at minimising the losses stemming from systemic financial risks. Macroprudential policy is aimed at making the system of financial intermediation more resilient to shocks and preventing the cyclical ${ }^{12}$ or structura ${ }^{13}$ vulnerability of the financial system (IMF-FSB-BIS, 2016). Although regulation is aimed at banks and other financial intermediaries, it also focuses beyond those (such as changes in the financial position of households, housing market processes, developments in foreign currency debt). Its toolset includes the capital and liquidity requirements under Basel III and debt cap regulations to curb household indebtedness (Loan to Value [LTV] and Debt to Income $[\mathrm{DTI}]$ indicators).

Accordingly, the earlier Jackson Hole consensus is amended by the macroprudential authority using its tools to

11 In addition to this see: the mentioned central bank websites.

12 Stemming from the procyclical changes in asset prices and loans, excessive outstanding debt or excessive leveraging, or fluctuations in financing.

13 Stemming from the structure of the financial market, the links between market participants and the crucial role of some players that are too big to fail. take countercyclical action in financial markets, while the central bank continues to intervene only when price stability is jeopardised.

The arguments in favour of this approach stem partly from the shortcomings of the alternative LATW policy, as summarised in the previous chapter. Although the traditional central bank instrument - i.e. the interest rate - impact both, price and financial stability are independent objectives; therefore, according to the Tinbergen rule (Tinbergen, 1952), achieving both of them concurrently requires at least two independent economic policy instruments. Arguments supporting the original Jackson-Hole consensus are still valid. Their premise is that market pricing is the most effective, and central banks cannot take over this role of the market. Central bank action against asset price bubbles is questionable. Amongst others, Stark (2010) emphasises the difficulties of assessing underlying factors of an asset price increase. In many cases, it is unclear whether the rise in prices on a specific market is excessive or consistent with economic fundamentals. In addition, an interest rate hike may have a negative impact on other asset prices that are not spoiled by the bubble. Thus monetary restriction may become counterproductive by inadvertently curbing essentially positive changes - such as growth-stimulating increase in investments - through the central bank's intervention. In addition, there is no way of knowing in advance what losses, if any, will ensue from the bursting of a bubble, and on the other side, the costs of pre-emptive central bank intervention. Bayoumi et al. (2014) concur with this view in that recognising the emergence of bubbles is not straightforward, and that the macroeconomic impacts of a bursting are difficult to forecast. For this reason, central banks face not only the challenge of deciding whether or not to intervene, but also of deciding when to do so and what degree of interest rate increase is to be applied to best curb the negative trends. In another paper (IMF, 2015), the IMF also noted that a delayed interest rate hike, when financial instability is already mature, only worsens the system further and may even trigger a crisis.

Although monetary policy is capable of mitigating risks through the interest rate, it is considered too blunt a tool by most. Besides Stark's (2010) opinion referred to earlier, Smaghi (2011) also emphasises that if a boom is limited to only a few sectors, the conventional monetary policy tool, i.e. the key policy rate hike, is not appropriate because the interest rate decision affects the entire system of financial intermediation. By contrast, macroprudential rules may be applied in a targeted, sector-specific manner. Yellen (2014) corroborates the opinions ${ }^{14}$ of the economic costs of higher interest rates applied in the context of LATW as presented in the previous chapter, referencing in Svensson (2016) and IMF (2015).

14 Svensson (2016) and IMF (2015). 
She draws attention to the impact of a potential drastic interest rate hike implemented for stability reasons, which, besides reducing financial system vulnerability, may have additional consequences (by making funding substantially more expensive and by delaying investments) such as higher debt expenditures for households or rising unemployment. This argument can also be interpreted as meaning that this consequence may contradict the Fed's current statutory mandate, as it would entail a departure both from the employment and, in the event of a deflation risk, the price stability objective.

In addition, the effectiveness of the central bank's conventional toolset, specifically a rise in short-term interest rates in an effort to offset growing bubbles, may also be questionable. Galí (2014) found that central bank interventions intended to prevent the formation or the growth of bubbles may increase asset price volatility.

Summing up what has been said so far, for the time being there is neither an adequate theoretical basis, nor convincing empirical evidence to support the explicit incorporation of financial cycle management into monetary policy. For now, counterarguments appear sounder and therefore, central bankers are unlikely to move away from the current monetary policy frameworks to a more uncertain territory. But the case is not closed, for two reasons. One is that the crisis drew attention to the unsustainable nature of the earlier consensus on the relationship between financial stability and monetary policy. The answer to this at present is that the financial stability mandate is predominantly within the competence of supervisory authorities, managed independently from monetary policy, and it does not explicitly integrate into the central bank's decision-making process. In this context, macroprudential supervision emerged alongside the reinforcement of traditional supervision, between monetary policy and microprudential supervision. The implementation of the modified Jackson Hole consensus also means that in terms of financial stability, the role of monetary authorities remains broadly unchanged while the supervisory and regulatory frameworks are to be radically transformed. However, we cannot ignore the defining trend of recent years in the context of which tasks and responsibilities of ensuring financial stability were added to the mandates of several central banks after the crisis: this mandate has been added to the statutes regulating central banks and their operation as an objective subordinated to price stability. In practice, this means that macroprudential supervision, and often microprudential supervision, has been integrated into the central bank body. In such a scenario, the central bank, as the supervisory authority, has the power to decide when to apply various macroprudential tools and under what conditions, but financial stability risk management is not directly included in the target function of monetary policy. The division of the various powers, regulated at the statutory level, into separate organisational and decision-making units addresses independence and separation of the different objectives.

\section{Macroprudential policy}

The question of how perfect this separation is within a single institution leads to another reason why the debate on the role of monetary policy in financial stability is still open. It inevitably calls into question how much the unconventional policy conducted by central banks recently jeopardises the objective of financial stability; whether macroprudential tools are adequate and sufficient for fostering financial stability; and what type of interaction is created between macroprudential tools and monetary policy. The following section looks at these challenges.

Firstly, one issue is that contrary to monetary policy, macroprudential regulation lacks both an explicit quantifiable final or intermediate objective and a clear, tried and tested toolset. Adequately defining objectives and finding and calibrating the right toolset is therefore a challenge. Furthermore, there is not enough experience on the effectiveness of macroprudential regulation in achieving the desired aim of preventing financial instability. The second challenge is, therefore, effectiveness. Thirdly, in the absence of practical experiences, we do not know how to adjust macroprudential regulation and monetary policy to be consistent with each other.

We have already mentioned the final and potential intermediate objectives of macroprudential policy. In their recommendations, the IMF-FSB-BIS (2016) note that macroprudential policy is unsuitable for achieving objectives other than the stability of the financial system. The IMF (2013) emphasises that macroprudential policy cannot be a substitute for a poorly functioning monetary policy. In other words, macroprudential policy cannot fulfil macroeconomic objectives nor it is able to correct the mistakes of macroeconomic policy. ${ }^{15}$

In the absence of practical experience, we can only presume what the impact of macroprudential regulation is. Yellen (2014) notes that although there is consensus that macroprudential tools will play a key role in ensuring financial stability in the future, there are no studies or empirical evidence on the potential macroeconomic impacts. As macroprudential policy affects the target variables of monetary policy, Woodford (2012) points out the necessity of the proper adjustment of, and close cooperation between these areas, alongside continuous communication and information sharing. In its paper, the IMF (2013) notes that sound monetary and macroprudential policy reinforce each other through multiple channels. An adequate macroprudential policy framework reduces the incidence and severity of financial shocks, which requires less frequent and sizeable LoLR intervention from the monetary authority and reduces the risk of the zero lower bound $(\mathrm{ZLB})^{16}$.

15 For example, macroprudential policy cannot be expected to correct growing external indebtedness resulting from a flawed macroeconomic decision.

16 According to conventional practice central banks influence the short term yields, but once the zero lower bound is reached, monetary policy looses this traditional room for manoeuvre: the usual toolset will be insufficient to implement further easing, offset deflationary pressure and stimulate demand. 
This in turn mitigates the need for extremely accommodative and unconventional monetary policy, reducing the associated moral hazard and boosting central bank credibility. This also improves the effectiveness of monetary policy. On the other hand, amid strongly anchored inflation expectations and less volatile and more predictable monetary policy, the cyclical issues faced by macroprudential policy are easier to manage.

At the same time, improper policy in either area (monetary or macroprudential policy) has negative impact on the other. Due to the lack of knowledge on the quantitative effects of macroprudential tools, it is difficult to calibrate the tools correctly; therefore, the potential deficiencies of macroprudential policy must also be considered. In the absence of relevant experience, the IMF (2013) has also warned of the danger of monetary policy misestimating the impact of macroprudential policy on the macroeconomic variables, which may lead to suboptimal decisions.

There has been little research so far on the success of macroprudential policy, and there is little actual experience in the area. One of the reasons is that the attention shifted to macroprudential policy only after the crisis; secondly, it has been introduced broadly within the Basel III framework only recently, and the introduction of some parts is still in progress. In terms of earlier experience, the use of macroprudential tools, as summarised by Smets (2014) based on Borio - Shim (2007) and Lim et al. (2011), was mainly characteristic of emerging countries in the past. Analyses addressing the pre-crisis period conclude that macroprudential rules have proven successful both in preventing excessive credit boom and asset price rise. At the same time, Smets (2014) draws attention to the need to calibrate tools correctly and to use multiple tools at the same time, as shown by the example of Spain, which failed to prevent the building-up of systemic risks and the outbreak of the crisis despite the adequate selection of tools. Lim et al. (2011) mention Spain as an example, where dynamic provisioning rules were introduced in the early 2000s. These were successful in terms of providing initial coverage for the emerging credit losses without decreasing capital. However, they were unable to curtail the spread of mortgage loans and the spike in property prices, and thus to prevent, or even mitigate, the effects of the crisis. Meanwhile, although the study finds the tool itself as effective, it emphasises poor calibration. Cerutti et al. (2015) came to conclusions similar to those earlier studies, concluding, based on a larger sample and a new period, ${ }^{17}$ that macroprudential tools curbed the expansion of outstanding loans and also shaped property price trends. Akinci \& OlmsteadRumsey (2015) came to the same conclusion, but emphasised that the tools targeting specific sectors were more effective than untargeted tools. For instance, the impact of macroprudential regulations on mortgage loans and property prices observed by the authors stemmed fully from specifically targeted macroprudential tools.

Overall, the use of macroprudential tools is a more promising area than application of LATW policy. The selection and calibration of the right tools will obviously be an important topic to be justified in practice and empirically in coming years. The fact that macroprudential regulation is more broadly accepted among central bankers than LATW also works in its favour. At the same time, ensuring the consistency of monetary policy and macroprudential policy is just as important of a challenge as the proper selection of tools. If both areas function smoothly, they may reinforce each other; however, a flaw in either one may have a negative impact on the other. Two risks can be identified in this regard. The implementation of Basel rules is a long and rigid process, essentially with no clear opportunity to revise the defined requirements. If these rules are not adequately calibrated, it may spur monetary policy to correct the flaw. This may lead to serious issues if monetary policy attempts to offset an excessively tight macroprudential framework, as this may have a negative impact on both objectives. Another source of problems is a scenario where the central bank conducts a sustained accommodative monetary policy using unconventional tools and macroprudential policy attempts to offset the negative impact of this loose stance of monetary policy on financial stability by using cyclical tools. In this case, a conflict of objectives may emerge, if just because of macroprudential action with an opposite effect, the central bank maintains or applies unconventional tools for longer or to a greater degree than it would be warranted otherwise. In our view, from the aspect of future developments in the financial stability mandate, it is crucially important to better understand and explore these conflicts of objectives.

\section{Conclusions}

This paper looked at the main challenges facing monetary policy regarding financial stability recently. Currently neither the theoretical background nor empirical experience provide compelling evidence or a reference for central bankers to move away from their existing monetary policy framework and adopt a leaning against the wind policy. Instead, the two objectives are handled separately, with financial stability being the mandate of macroprudential policy, while price stability falls within the competence of monetary policy. However, the debate remains open for two reasons: firstly, there is some uncertainty regarding the success of macroprudential regulation and its proper cooperation with monetary policy and secondly, the theoretical development of the LATW may also yield results.

17 The practice of 119 (advanced and emerging) countries was examined over the 2000-2013 period. 


\section{References}

Akinci, O., Olmstead-Rumsey, J. (2015). How Effective are Macroprudential Policies? An Empirical Investigation. Board of Governors of the Federal Reserve System. International Finance Discussion Papers No. 1136. May 2015.

Bayoumi, T., Dell'Ariccia,G., Habermeier, K., Mancini-Griffoli,T., Valencia, F., anIMF Staff Team (2014). Monetary Policy in the New Normal. IMF Staff Discussion Note. April 2014.

Blot, C., Creel, J., Hubert, P., Labondance, F., Saraceno, F. (2015). Assessing the Link between Price and Financial Stability. Journal of Financial Stability. 16, pp. 71-88. https://doi.org/10.1016/j.jfs.2014.12.003

Borio, C., Juselius, M., Disyatat, P., Drehmann, M. (2016). Monetary policy, the financial cycle and ultralow interest rates. BIS Working Papers No 569. July 2016.

Borio, C., Shim, I. (2007). What Can (Macro-)Prudential Policy Do to Support Monetary Policy? BIS Working Paper No. 242.

CEPR (2013) Is Inflation Targeting Dead? Central Banking After the Crisis. (Reichlin, L., Baldwin, R.:(Eds.)). CEPR e-book, 2013. URL: http://voxeu.org/sites/default/files/file/P248\%20inflation\%20targeting\%207\%20 may.pdf

Cerutti, E., Claessens, S., Laeven, L. (2015). The Use and Effectiveness of Macroprudential Policies: New Evidence. IMF Working Paper No. 15/61. 2015.

Galí, J. (2014). Monetary Policy and Rational Asset Price Bubbles. American Economic Review. 104(3), pp. 721-752. https://doi.org/10.1257/aer.104.3.721

Gelain, P., Lansing., K. J., Natvik, G. J. (2015). Leaning against the credit cycle. Norges Bank Working Paper. April 2015.

IMF (2013). Unconventional Monetary Policy: Recent Experiences and Prospects, IMFPolicy Paper, Washington: International Monetary Fund. April 2013.

IMF (2015). Monetary policy and Financial Stability. IMF Staff Report. 28th August 2015.

IMF-FSB-BIS (2016). Elements of Effective Macroprudential Policies, Lessons from International Experience. 31st August 2016.
Issing, O. (2009). Asset Prices and Monetary Policy. Cato Journal. 29(1), pp. 45-51.

Lim, C., Columba, F., Costa, A., Kongsamut, P., Otani, A., Saiyid, M., Wezel, T., Wu, X. (2011). Macroprudential Policy: What Instruments and How to Use Them? Lessons from Country Experiences. IMF Working Paper No. 11/238.

Nelson, B., Pinter, G., Theodoridis, K. (2015). Do contractionary monetary policy shocks expand shadow banking? Bank of England Working Paper No. 521. January 2015.

Olsen, Ø. (2015). Integrating Financial Stability and Monetary Policy Analysis. Speech by Governor (of Norges Bank) Øystein Olsen, Systemic Risk centre, Londol School of Economics, 27 April 2015.

Smaghi, L. B. (2011). Macro-prudential supervision and monetary policy linkages and demarcation lines. Speech. Annual Economic Conference on "The Future of European Integration: Some Economic Perspectives". Vienna, 23 May 2011.

Smets, F. (2014). Financial Stability and Monetary Policy: How Closely Interlinked? International Journal of Central Banking. 10(2), pp. 263-300.

Stark, J. (2010). In search of a robust monetary policy framework, Keynote speech by Jürgen Stark, Member of the Executive Board, at the 6th ECB Central Banking Conference "Approaches to monetary policy revisited - lessons from the crisis", Frankfurt am Main, 19 November 2010 of the ECB, ECB Speeches, 19 November 2010.

Svensson, L. E. O. (2016). Cost-Benefit Analysis of Leaning Against the Wind: Are Costs Larger Also with Less Effective Macroprodential Policy? IMF Working Paper WP/16/3. January 2016.

Tinbergen, J. (1952). On the Theory of Economic Policy, North-Holland Publishing Company, 2nd edition.

Toniolo, G., White, N. E. (2015). The Evolution of the Financial Stability Mandate: From its Origins to the Present Day. NBER Working Paper No. 20844. January 2015. https://doi.org/10.3386/w20844

Woodford, M. (2012). Inflation Targeting and Financial Stability. NBER Working Paper 17967. April 2012. https://doi.org/10.3386/w17967

Yellen, J. (2014). Monetary Policy and Financial Stability. Speech at the 2014. Michael Camdessus Central Banking Lecture, IMF, 2nd July 2014. 